\title{
Erratum to: Short tangential arcs in VMAT based breast and chest wall radiotherapy lead to conformity of the breast dose with lesser cardiac and lung doses: a prospective study of breast conservation and mastectomy patients
}

\author{
Anusheel Munshi ${ }^{1} \cdot$ Biplab Sarkar $^{1} \cdot$ Satheeshkumar Anbazhagan $^{1}$. \\ Upendra K. Giri ${ }^{1} \cdot$ Harpreet Kaur $^{1} \cdot$ Kanan Jassal $^{1} \cdot$ Tharmar Ganesh $^{1}$ • \\ Bidhu Kalyan Mohanti ${ }^{1}$
}

Published online: 12 June 2017

(C) Australasian College of Physical Scientists and Engineers in Medicine 2017

Erratum to: Australas Phys Eng Sci Med

DOI 10.1007/s13246-017-0558-y

The original version of this article was corrected: the name of the third author is Satheeshkumar Anbazhagan. 